\title{
Project SB Brasil 20 I0: individual and contextual factors that have impact on dental caries prevalence
}

\begin{abstract}
IThere is a clear decline in caries experienced by the world population in recent decades. The dissemination of fluoride use, combined with the public health politics that facilitate the population's access to oral health services, has been identified as the main causes of the current pattern of caries development in Brazil. However, other variables may be involved in decay of caries. The objective of this study was to identify individual and contextual variables associated with caries prevalence in 12,614 individuals allocated to the 12-year age group and to the 15 to 19 age group, examined in the last epidemiological survey of oral health in Brazil-SB Brasil 2010. The variables evaluated were: "age group", "dental caries", "family income", "educational level", "frequency of use of dental services" and "self-perception and impact of oral health status". The contextual variables analyzed were: 'Child Benefit', National Health System Development Index (IDSUS), 'Human Development Index (HDI)' and 'presence/absence of fluoridated water treated water' were collected from data secondary databases in the public and inter- institutional database of the Department of Primary Health Care of the Brazilian Ministry of Health. The results showed that the self-perception of the need for dental treatment, as well as the report of tooth pain, is variables directly related to the predisposition of caries development in this population. The value of the IDSUS greater than 5.76 and the presence of fluoridated water in the municipalities were considered as protective factors against caries. It was concluded that, in addition to the policies for fluoridation of treated water and access to oral health services in SUS, adequate planning of oral health actions should address issues according to the local population.
\end{abstract}

Keywords: epidemiology, public health, oral health, dental caries, DMF index, dental health, surveys
Volume 9 Issue 3 - 2018

\author{
Valéria Silva Candido Brizon,' Sabrina \\ Hundertmarch Paz,' Dióger dos Santos Paz,' \\ Glaucia Maria Bovi Ambrosano, ${ }^{2}$ Francisco \\ Carlos Groppo, ${ }^{3}$ Gabriela Rojas Soto,' \\ Antonio Carlos Pereira,' Karine Laura \\ Cortellazzi Mendes,' Renato Pereira da Silva ${ }^{4}$ \\ 'Department of Social Dentistry, State University of Campinas, \\ Brazil \\ ${ }^{2}$ Department of Biostatistics, State University of Campinas, \\ Brazil \\ ${ }^{3}$ Department of Physiological Sciences, State University of \\ Campinas, Brazil \\ ${ }^{4}$ Department of Nutrition and Health, Federal University of \\ Viçosa/ Center of Biological Sciences II, University Campus, \\ Brazil
}

Correspondence: Dioger dos Santos Paz, Department of Social Dentistry, School of Dentistry of Piracicaba, State University of Campinas, Av. Limeira, $\mathrm{n}^{\circ}$ 901, district:Areião, Piracicaba, São Paulo, SP, Mailbox 52, CEP: | 34 | 4-903, Brazil, Email diogerspaz@gmail.com

Received: April 30, 2018| Published: May 17, 2018

\section{Introduction}

The national epidemiological oral health surveys conducted in the last few decades have shown evidence of the decline and polarization of caries experienced in different countries in the world, ${ }^{1}$ as has also been verified in Brazi. ${ }^{2}$ The action of fluoridated public water supply and dentifrices (McDonagh et al., 2000; Marinho et al., 2004), potentiated by the impact of public health policies ${ }^{2,3}$ have contributed to the present profile of this disease in Brazil (Brasil, 2011). Together to the effects of fluorides and public health policies, various authors have reported the effect of individual and contextual variables, to some degree, on the health-disease process relative to oral conditions, showing evidence of its multifactorial nature.$^{3-7}$ Among these variables, family income has been one of the most widely studied and reported as being associated with caries prevalence. ${ }^{7}$ The importance of the education of the parents' of children and adolescents in determining the etiology of caries, has also been consolidated. ${ }^{6}$ In addition to these factors, self-perception of oral health status and forms of access to public oral health services have also been found to be associated with the prevalence of caries in diverse populations (Borges et al., 2008; Brasil, 2011). In the context in which the individual is inserted, the Family Financial Grant Program is emphasized. This is a Brazilian program for the distribution of income to families in a situation of poverty and extreme poverty, with the goal of overcoming the situation of vulnerability to which these families are exposed, with regard to their basic social rights in the areas of education health and social assistance. ${ }^{8}$ To elucidate the manner in which these variables are related to the prevalence of caries must be the trigger for more precise planning of actions in health, with a view to improving of the oral health condition of populations. Thus, the aim of this study was to identify individual and contextual variables associated with caries prevalence in 12614 individuals allocated to the age group of 12, and group from 15 to 19 years, examined in the last epidemiological oral health survey in Brazil-SB Brasil 2010. ${ }^{9}$

\section{Methods}

This article was prepared from the analysis of secondary data originated in the "Projeto SB Brasil 2010", and obtained from the public and inter-institutional databases available at the following electronic address http://dab.saude.gov.br/cnsb/solicitacao_bd sb2010.php, of the Department of Primary Care (DAB) of the Ministry of Health of Brazil. The project SB Brasil 2010, ${ }^{9}$ was approved by the Ethics Committee on Research with Human Beings, Protocol No.009/2010. The Term of Free and Informed Consent was obtained from all individuals who participated in the study. This project consisted of an epidemiological survey of the oral health conditions of the Brazilian population in diverse age groups, in order to obtain epidemiological data capable of subsidizing the elaboration of guidelines for a national oral health policy, in addition to actions to strengthen the management of oral health public services in the different spheres of government. Clinical data were obtained from dental exams performed in accordance with the methodology proposed by the World Health Organization, while data relative to the 
socioeconomic condition, self-evaluation of oral health, and access to dental services were collected by means of questionnaires. ${ }^{9}$ A number from 01 to 250 participants per city were evaluated in 176 cities in Brazil, totaling a final study sample of 12614 individuals allocated to the group of 12 years old, and the age group from 15 to 19 years of age. The sampling technique used by SB Brasil 2010 was probabilistic by/through conglomerates. For this purpose, three stratifications were used: The first used Domains and Primary Sampling Units: capitals and municipalities of the interior, according to macro-region. The second consisted of subdivision of the participating municipalities: 27 capitals plus 30 municipalities in the interior in each region. The third was performed by lottery to guarantee representativeness in the municipalities, census sectors and domiciles. The individual independent variables (relative to age group, demographic data, oral health diseases, socioeconomic data, educational level, morbidity, use of dental services and self-perception and impact of oral condition on health), and the contextual variables (Family Financial Grant-'Child Benefit', National Health System Development Index (IDSUS), Human Development Index (HDI) and Interaction GNP/fluoridated water initially analyzed by descriptive statistics. Subsequently we proceeded with multilevel multiple logistic regression analysis. Adopting a level of significance $\alpha=0.05(5 \%)$, performed in the statistical software package SAS System 9.2 for Windows ${ }^{\circledR}$. The prevalence of caries in permanent teeth was considered dichotomized into zero, and higher than zero as response variable. Initially bivariate analyses between the studied variables and response variable were performed by means of the Chi-square or Exact Fisher tests. After this, a multilevel logistic regression model was estimated, considering the individual variables as Level 1 and the contextual variables as Level 2. For this purpose, the PROC GLIMMIX procedure was used; that is, "Generalized Linear Models-Mixed", specifying the logit link function and binary response variable. Adjustment of the model was evaluated by -2 Res Log Likelihood. In all the statistical models of this analysis, the significances were controlled by the other predictors of the model.

\section{Results}

Descriptive analysis of the individual independent variables may be observed in Table 1 .

The sample was composed of 12614 participants; of these $57.45 \%$ were composed of 12 -year-old children, and $42.55 \%$ of adolescents in the age-range from 15 to 19 years. The major portion of those examined $(81.50 \%)$ resided in the capitals of the different Brazilian states selected in the Project SB Brasil 2010; ${ }^{9}(18.55 \%)$ of the individuals researched had severe, or very severe malocclusion. The majority, $(69.70 \%)$, of the participants needed some type of treatment. Approximately $71 \%$ of the individuals came from families with a monthly income of up to 1500 reais, among whom fewer than $42 \%$ of the parents and/or those responsible for the home were studying at, or had a university title. As regards the self-reported oral health status, $68.51 \%$ perceived they needed treatment, and $24.02 \%$ informed having felt toothache in the 6 months prior to the dental exams of the SB Brasil 2010 Project. With respect to the manner in which individuals had access to oral health services, $83.74 \%$ were found to have access to the dentist, and of these, $59.86 \%$ had visited the dentist in a period shorter than 1year, and $51.45 \%$ used the public dental service. Pain, tooth extraction and other types of curative treatment still persist as the main cause of making an appointment with the dentist, and this was reported by $63.89 \%$ of the individuals. The majority of those examined $(63.86 \%)$ did not report any dental impact on the performance of their daily activities. With regard to the contextual variables, it was verified that $51.57 \%$ of the cities from which the participants came, were contemplated by the Family Financial Grant Program (Bolsa Família-BF). The majority of these municipalities $(63.56 \%)$ received scores higher than 5.76 for IDSUS. Nevertheless, these scores will still lower than score 7.00, the cut-off score for a satisfactory performance of SUS. A high HDI, over 0.80 was found in $47.62 \%$ of the municipalities in which the dental exams were performed. The interaction between GNP and fluoridated water was found in the majority of the municipalities of this study (Table 2). As follows, we present the different multilevel models estimated for this study (Table 3). In Model 1, it may be observed that the mean caries prevalence in the cities of the sample was 0.671 , with standard error of 0.019 . When the variables of the individual level were included (Model 2) higher prevalence was observed in individuals in the age-range from 15 to 19 years of age, with an income lower than $\mathrm{R} \$ 1500(\mathrm{p}<0.001)$, who needed treatment $(\mathrm{p}<0.001)$, had higher CPI scores $(p<0.001)$, with greater perception of treatment need $(p<0.001)$, had toothache $(\mathrm{p}<0.001)$ and who had greater oral impact on daily performance (OIDP). The influence of individual and contextual variables on the variability of caries prevalence is presented in Model 3 (Table 4).

Table I Frequency and percentage per category of individual qualitative independent variables

\begin{tabular}{|c|c|c|c|c|}
\hline Variables & & & Frequency & Percentage (\%) \\
\hline \multirow{5}{*}{ General Information } & \multirow{2}{*}{ Age } & 12 years & 7247 & 57.45 \\
\hline & & 15 to 19years & 5367 & 42.55 \\
\hline & \multirow{3}{*}{ Capital } & Capital & 9672 & 81.5 \\
\hline & & Interior & 2196 & 18.5 \\
\hline & & North & 3047 & 31.42 \\
\hline \multirow[t]{7}{*}{ Demographic } & & Northeast & 2224 & 22.93 \\
\hline & \multirow[t]{3}{*}{ Region } & Southeast & 1299 & 13.39 \\
\hline & & South & 1066 & 10.99 \\
\hline & & Midwest & 2063 & 21.27 \\
\hline & \multirow{2}{*}{ DAI Classification } & Without malocclusion/Malocclusion defined & 8202 & 81.45 \\
\hline & & Severe malocclusion/Very severe malocclusion & 1907 & 18.55 \\
\hline & \multirow{2}{*}{ Treatment Need } & Does not require & 3835 & 30.4 \\
\hline \multirow[t]{3}{*}{ Oral Health Diseases } & & Does require & 8779 & 69.7 \\
\hline & \multirow{2}{*}{$\begin{array}{l}\text { CPI - Community } \\
\text { Periodontal Index }\end{array}$} & Healthy & 6654 & 54.24 \\
\hline & & $\begin{array}{l}\text { Bleeding/Calculus/Pocket } 4-5 \mathrm{~mm} / \text { Pocket of } 6 \\
\mathrm{~mm} \text { or more }\end{array}$ & 5614 & 45.76 \\
\hline
\end{tabular}


Table continuded

\begin{tabular}{|c|c|c|c|c|}
\hline Variables & & & Frequency & Percentage (\%) \\
\hline \multirow{6}{*}{ Socioeconomic data } & \multirow{2}{*}{ Number of persons } & $\leq 4$ & 6399 & 50.79 \\
\hline & & $>4$ & 6201 & 49.21 \\
\hline & \multirow{2}{*}{$\begin{array}{l}\text { Number of Goods/ } \\
\text { Assets* }\end{array}$} & $\leq 7$ & 7675 & 61.26 \\
\hline & & $>7$ & 4854 & 38.74 \\
\hline & \multirow{2}{*}{ Income per capita* } & $\leq 1,500.00$ & 8508 & 71.44 \\
\hline & & $>1500.00$ & 3402 & 28.56 \\
\hline \multirow{17}{*}{$\begin{array}{l}\text { Schooling, morbidity } \\
\text { and use of dental } \\
\text { services Self-perception } \\
\text { and Impact on health }\end{array}$} & \multirow{2}{*}{ Years of Schooling* } & $\leq 7$ & 7372 & 58.6 \\
\hline & & $>7$ & 5209 & 41.4 \\
\hline & \multirow{2}{*}{$\begin{array}{l}\text { Perception of Need } \\
\text { for Treatment }\end{array}$} & No & 3794 & 31.49 \\
\hline & & Yes & 8253 & 68.51 \\
\hline & \multirow{2}{*}{$\begin{array}{l}\text { TOOTHACHE (in last } \\
6 \text { months) }\end{array}$} & No & 9546 & 75.98 \\
\hline & & Yes & 3018 & 24.02 \\
\hline & \multirow{2}{*}{ Visit to the dentist } & No & 2037 & 16.26 \\
\hline & & Yes & 10489 & 83.74 \\
\hline & \multirow{3}{*}{$\begin{array}{l}\text { Frequency of } \\
\text { Consultation }\end{array}$} & Less than Iyear & 6197 & 59.86 \\
\hline & & I to 2 years/ & 4155 & 40.14 \\
\hline & & 3 or more years & & \\
\hline & \multirow{2}{*}{$\begin{array}{l}\text { Where did your last } \\
\text { visit occur? }\end{array}$} & Public Service & 5359 & 51.45 \\
\hline & & Private Service/Health Insurance/Plans & 5056 & 48.55 \\
\hline & \multirow{2}{*}{$\begin{array}{l}\text { Reason for } \\
\text { consultation }\end{array}$} & Review/Prevention & 3756 & 36.14 \\
\hline & & Pain/Extraction/Treatment & 6636 & 63.86 \\
\hline & \multirow{2}{*}{ OIDP } & 0 & 8055 & 63.86 \\
\hline & & $\geq 1$ & 4559 & 36.14 \\
\hline
\end{tabular}

Table 2 Frequency and percentage per category of contextual qualitative independent variables

\begin{tabular}{|c|c|c|c|c|}
\hline \multicolumn{3}{|l|}{ Variables } & \multirow{2}{*}{$\begin{array}{l}\text { Frequency } \\
6467\end{array}$} & \multirow{2}{*}{$\begin{array}{l}\text { Percentage (\%) } \\
51.57\end{array}$} \\
\hline \multirow{10}{*}{ Contextual } & \multirow{2}{*}{ Family Financial Grant } & $\leq 55.81$ & & \\
\hline & & $>55.81$ & 6147 & 48.73 \\
\hline & \multirow{2}{*}{ IDSUS (scores) } & $\leq 5.76$ & 6470 & 36.44 \\
\hline & & $>5.76$ & 6144 & 63.56 \\
\hline & \multirow{2}{*}{ HDI } & $\leq 0.800$ & 6607 & 52.38 \\
\hline & & $>0.800$ & 6007 & 47.62 \\
\hline & \multirow{4}{*}{ Interaction (GNP and fluoridated water) } & $\leq 14921.92$ without Fluoride & 1855 & 15.46 \\
\hline & & $\leq 14921.92$ with Fluoride & 4700 & 39.16 \\
\hline & & $>14921.92$ without Fluoride & 750 & 6.25 \\
\hline & & $>14921.92$ with Fluoride & 4697 & 39.13 \\
\hline
\end{tabular}

Table 3 Multilevel multiple logistic regression analysis (Models I and 2) for individual variables in I2-year-old children and adolescents from 15 to 19 years of age, Brasil, 2010

\begin{tabular}{llllll}
\hline & \multicolumn{2}{c}{ Model I } & \multicolumn{2}{c}{ Model 2 } \\
& (Only the intercept) & \multicolumn{2}{c}{ (Individual Variables) } & \\
& Estimate (SE) & p-value & Estimate (SE) & Odds ratio & p-value \\
\hline Intercept & $0.671(0.019)$ & $<0.001$ & $-1.546(0,062)$ & & $<0.001$ \\
Individual & & & & \\
Age (Ref.' ': I2 years) & & $1.383(0.053)$ & 3.98 & $<0.001$ \\
Treatment Need (Ref'.: No) & & $1.962(0.053)$ & 7.11 & $<0.001$ \\
\hline
\end{tabular}

Citation: Brizon VSC, Paz SH, Paz DS, et al. Project SB Brasil 2010: individual and contextual factors that have impact on dental caries prevalence.J Dent Health Oral Disord Ther. 2018;9(3):I68-172. DOI: I0.15406/jdhodt.20I8.09.00372 
Table continuded

\begin{tabular}{|c|c|c|c|c|c|}
\hline & \multicolumn{2}{|c|}{$\begin{array}{c}\text { Model I } \\
\text { (Only the intercept) }\end{array}$} & \multicolumn{2}{|c|}{$\begin{array}{c}\text { Model } 2 \\
\text { (Individual Variables) }\end{array}$} & \multirow[b]{2}{*}{ p-value } \\
\hline & Estimate (SE) & p-value & Estimate (SE) & Odds ratio & \\
\hline $\mathrm{CPI}^{2}$ (Ref.': Healthy & & & $0.262(0.048)$ & 1.3 & $<0.001$ \\
\hline Toothache Ref'.: No) & & & $0.555(0.065)$ & 1.74 & $<0.001$ \\
\hline OIDP2 (Ref.': zero) & & & $0.171(0.054)$ & 1.18 & 0.015 \\
\hline -2 Res Log Likelihood & 16143.01 & & | I 284.7 & & \\
\hline
\end{tabular}

'Ref.= Reference; ${ }^{2} \mathrm{CPI}=$ Community Periodontal Index; ${ }^{3} \mathrm{OIDP}=$ Oral Impact on Performance

Table 4 Multilevel multiple logistic regression analysis (Model 3) for individual and contextual variables in 12 -year-old children and adolescents from 15 to 19 years of age, Brasil, 2010

\begin{tabular}{|c|c|c|c|}
\hline & \multicolumn{3}{|c|}{$\begin{array}{c}\text { Model } 3 \\
\text { (Individual and contextual variables) }\end{array}$} \\
\hline & Estimate (SE) & Odds ratio & p-value \\
\hline Intercept & $-1.131(0.090)$ & & $<0.001$ \\
\hline \multicolumn{4}{|l|}{ Individual } \\
\hline Age (Ref.': I 2 years) & I.379 (0.055) & 3.97 & $<0.001$ \\
\hline Treatment Need (Ref'.: No) & $1.953(0.054)$ & 7.05 & $<0.001$ \\
\hline CPI (Ref.': Healthy & $0.231(0.050)$ & 1.26 & $<0.001$ \\
\hline Income (Ref, ${ }^{\prime}: \leq 1500$ & $-0.179(0.053)$ & 0.84 & 0.008 \\
\hline $\begin{array}{l}\text { Perception of Dental } \\
\text { Treatment Need (Ref'.: No) }\end{array}$ & $0.331(0.053)$ & 1.39 & $<0.001$ \\
\hline Toothache (Ref'.: No) & $0.595(0.068)$ & $1.8 \mathrm{I}$ & $<0.001$ \\
\hline OIDP (Ref.': zero) & $0.211(0.056)$ & 1.23 & 0.002 \\
\hline \multicolumn{4}{|l|}{ Contextual } \\
\hline $\begin{array}{l}\text { GNP high with fluoride } \\
\text { (Ref: Low and without) }\end{array}$ & $-0.576(0.084)$ & 0.56 & $<0.001$ \\
\hline IDSUS4 (Ref: $\leq 5.76$ & $-0.118(0.057)$ & 0.89 & 0.041 \\
\hline $\begin{array}{l}\text { GNP5 low with fluoride } \\
\text { (Ref: Low and with) }\end{array}$ & $-0.292(0.078)$ & 0.75 & 0.002 \\
\hline $\begin{array}{l}\text { GNP high with fluoride } \\
\text { (Ref: Low and with) }\end{array}$ & $0.091(0.129)$ & 1.09 & 0.483 \\
\hline -2 Res Log Likelihood & 10535.47 & & \\
\hline
\end{tabular}

'Ref.= Reference; ${ }^{2} \mathrm{CPI}=$ Community Periodontal Index; ${ }^{3} \mathrm{OIDP}=$ Oral Impact on Performance; ${ }^{4}$ IDSUS $=$ National Health System Performance Index $;{ }^{5} \mathrm{GNP}=$ Gross National Product

In Model 3, the individual and contextual variables were worked on. For caries prevalence, the following individual variables were significant: those in which the participants had treatment needs $(\mathrm{p}<0.001)$, those who had some gingival alteration, such as bleeding, calculus, and/or pocket larger than $4 \mathrm{~mm}(\mathrm{CPI}-\mathrm{p}<0.001)$, whose family income was lower than or equal to $R \$ 1500.00(p=0.008)$, who reported they perceived need for treatment $(\mathrm{p}<0.001)$, felt toothache $(\mathrm{p}<0.001)$ and participants who reported they had oral alteration and this had an impact on their daily life performance (OIDP). For the contextual variables, the following were significant: cities that received IDSUS scores equal to or lower than 5,76 and the interaction (GNP and fluoridation) was low (low GNP and had no fluoridated water for consumption).

\section{Discussion}

The aim of the present study was to identify the individual and contextual variable that showed some impact on the prevalence of caries in the sample of the last national epidemiological oral health survey, the Project SB Brasil 2010. The multifactorial nature of the etiology of this disease, recognized for decades in the scientific literature, was corroborated by the results found. Among the individuals examined, it was observed that those who presented a Community Periodontal Index differing from zero also presented greater risk for presenting caries prevalence differing from zero. This result was corroborated by the study of Merchant, ${ }^{10}$ in which the direct relationship between periodontal disease, notably in its severe form, and caries was reported. However, only $0.7 \%$ of the sample between the ages of 15 to 19 years presented a deep periodontal pocket. Previous studies ${ }^{11,12}$ have related a better family income as protective factor, including the study of Borges et al., 2008, in which the secondary data of Project SB Brasil, in its 2002-2003 edition, were also verified in the present study. It should be emphasized that income is normally articulated with other variables that also have an impact on the health of individuals, such as, for example, educational level, number of individuals and consumer goods in a home (Gonçalves et al., 2002; Borges et al., 2008; Leão et al., 2012). Nevertheless, no other socioeconomic variable obtained significance to compose the statistical model.

The self-reported, subjective need for treatment in health has also been explored in epidemiological surveys, since it is simple to obtain, and it is possible to associate it with objective traditional health indicators (Reichert et al., 2012). The assumption of need for dental treatment shows the importance individuals attribute to oral health, and together with the objective indicators of oral health, guides the planning and execution of dental actions in the sphere of public oral health care. The presence of pain and the definition of the extent to which dental problems have impact on the daily life of individuals has been shown to be important in determining how individuals access the public dental services, because up to now, no interval between routine consultations, proved to be scientifically efficient, has yet been defined (Davenport et al., 2003). Nevertheless, periodic visits are important for maintenance of dentition (Cunha-Cruz et al., 2004). Thus, individuals who reported pain in any tooth during a dental exam, present more chance of having a DMF index differing from zero $(\mathrm{OR}=1.81)$. In the studied sample, individuals who perceived the need for treatment $(\mathrm{OR}=1.39)$ or who had an OIDP $(\mathrm{OR}=1.23)$ also presented greater chance of having a DMF index differing from zero. One of the strategies for reducing the inequalities in oral health, resulting from the unequal distribution of public health services and income, is public water supply fluoridation. ${ }^{3}$ This measure, in addition to the growing consumption of fluoridated dentifrices, has been recognized worldwide as contributing to the reduction of the burden of caries (McDonagh et al., 2000; Marinho et al., 2004). However, later studies conducted in the State of São Paulo, Brazil, found no statistically significant difference in the prevalence of caries between municipalities with and without water supply fluoridation for the 12-year-old Group ${ }^{4}$ and the age Group from 15 to 19 years. ${ }^{11}$ The protective factor of fluoridated water was found in this study, 
corroborating the findings of previous systematic reviews (McDonagh et al., 2000; Marinho et al., 2004) and findings later ${ }^{7}$ than the results of exams performed in Project1 SB Brasil 2010. ${ }^{9}$ However, it was found that the protective effect of fluoridated water on the prevention of caries was more evident in municipalities whose GNP was higher, reinforcing the multifactorial nature itself of the etiology of caries disease. In spite of being discrete, the protective effect of a higher income (individual variable) and a higher IDSUS value (contextual variable), although still below the ideal, must be equally considered in the planning of actions in health with a view to improve the nosological condition relative to oral diseases, considering that the importance of these variables will be perceived in the short and long term in the health of the population.

\section{Conclusion}

From the results found, it was possible to delineate the behavior of individual and contextual variables in the etiology and prevalence of caries in Brazil in the year 2010, for the studied age range. Therefore, health managers and professionals directly involved in public health must pay special attention to the policies of strengthening SUS, with a view to its better qualification, and access to users, in addition to the maintenance and/or expansion (where necessary) of the policy of public water supply fluoridation. Health professionals must also pay special attention to identifying the health status and self-reported need for treatment, which are also risk factors for the development of caries in the Brazilian population. ${ }^{13-19}$

\section{Acknowledgements}

None.

\section{Conflict of interest}

The authors declare that there is no conflict of interest

\section{References}

1. Marthaler TM. Changes in dental caries 1953-2003. Caries Research 2004;38(3):173-181.

2. Ministério da Saúde. Secretaria de Atenção à Saúde. Departamento de Atenção Básica. Projeto SB Brasil 2003: condições de saúde bucal da população brasileira 2002-2003: resultados principais. Brasília: Ministério da Saúde; 2004.

3. Frias AC, Antunes JLF, Junqueira SR, et al. Determinantes individuais e contextuais da prevalência de cárie dentária não tratada no Brasil. . Revista Panamericana de Salud Publica. 2007;22(4):279-285.

4. Moimaz, SAS, Costa ACO, Silva LP, et al. A comparative analysis of caries and fluorosis among cities with and without public water supply fluoridation in São Paulo State, Brazil. Revista Odonto Ciência. 2010;25(1):15-19.
5. Celeste RK, Fritzell J, Nadanovsky P. The relationship between levels of income inequality and dental caries and periodontal diseases. Cad Saúde Pública. 2011;27(6):1111-1120.

6. Ferreira LL, Brandão GAM, Garcia G, et al. Odontalgia associada a variáveis socioeconômicas, psicossociais e saúde bucal. Revista Dor. 2012;13(4):343-349.

7. Lisboa CM, Paula JS, Ambrosano GMB, et al. Socioeconomic and family influences on dental treatment needs among Brazilian underprivileged schoolchildren participating in a dental health program. BMC Oral Health. 2003;13:56.

8. Brasil, Ministério da Saúde, Coordenação Geral de Saúde Bucal. Banco de dados da Pesquisa Nacional de Saúde Bucal - Projeto SB Brasil 2010". 2013.

9. Roncalli AG. The SB Brasil 2010 Project: a key strategy for developing an oral health surveillance model. Cadernos de Saúde Pública. 2010;26(3):428-429.

10. Merchant AT. Periodontitis and dental caries occur together. Journal of Evidence-Based Dental Practice. 2012;12(3):18-19.

11. Gushi LL, Soares MC, Forni TIB, et al. Cárie dentária em adolescentes de 15 a 19 anos de idade no Estado de São Paulo, Brasil, 2002. Cadernos de Saúde Pública. 2005;21(5):1383-1391.

12. Meneghim MC, Kozlowski FC, Pereira AC, et al. Classificação socioeconômica e sua discussão em relação à prevalência de cárie e fluorose dentária. Ciência \& Saúde Coletiva. 2007;12(2):523-529.

13. Cortellazzi KL, Tagliaferro EPS, Assaf AV, et al. Influência de variáveis socioeconômicas, clínicas e demográfica na experiência de cárie dentária em pré-escolares de Piracicaba, SP. Revista Brasileira de Epidemiologia. 2009;12(3):490-500.

14. Leroy R, Bogaerts K, Lesaffre E, et al. Effect of Caries Experience in Primary Molars on Cavity Formation in the Adjacent Permanent First Molar. Caries Researc. 2005;39(5):342-349.

15. Lucas SD, Portela MC, Mendonça MC. Variações no nível de cárie dentária entre crianças de 5 e 12 anos em Minas Gerais, Brasil. Cadernos de Saúde Pública. 2005;21(1):55-63.

16. Moreira PVL, Rosenblatt A, Passos IA. Prevalência de cárie em adolescentes de escolas públicas e privadas na cidade de João Pessoa, Paraíba, Brasil. Ciência \& Saúde Coletiva. 2007;12(5):1229-1236.

17. Narvai PC, Frazão P, Roncalli AG, et al. Cárie dentária no Brasil: declínio, iniquidade e exclusão social. Revista Panamericana de Salud Public. 2006;19(6):385-93.

18. Pine CM, Curnow MM, Burnside G, et al. Caries prevalence four years after the end of a randomized controlled trial. Caries Res. 2007;41(6):431-436.

19. Spolidorio DM, Hofling JF, Moreira D, et al. Dental caries status in deciduos and permanent dentition of Brazilian children aged 6-8 years with a socioeconomic base. Brazilian Journal of Oral Science. 2003;2(4): 147-150. 